Revista de la red interuniversitaria de estudios sobre las literaturas rioplatenses contemporáneas en Francia

$7 \mid 2012$

Arqueologías

\title{
Escribir contra la ciudad: fotos y texto en Prosa del observatorio de Julio Cortázar
}

\section{Marcy Schwartz}

\section{OpenEdition}

\section{Journals}

Edición electrónica

URL: http://journals.openedition.org/lirico/652

DOI: $10.4000 /$ lirico. 652

ISSN: 2262-8339

Editor

Réseau interuniversitaire d'étude des littératures contemporaines du Río de la Plata

\section{Referencia electrónica}

Marcy Schwartz, «Escribir contra la ciudad: fotos y texto en Prosa del observatorio de Julio Cortázar »,

Cuadernos LIRICO [En línea], 7 | 2012, Puesto en línea el 11 octubre 2012, consultado el 19 abril 2019.

URL : http://journals.openedition.org/lirico/652 ; DOI : 10.4000/lirico.652

Este documento fue generado automáticamente el 19 abril 2019.

\section{(c) $(1) \odot \ominus$}

Cuadernos LIRICO está distribuido bajo una Licencia Creative Commons Atribución-NoComercialSinDerivar 4.0 Internacional. 


\title{
Escribir contra la ciudad: fotos y texto en Prosa del observatorio de Julio Cortázar
}

\author{
Marcy Schwartz
}

1 A lo que la fotografía latinoamericana no puede escapar, y los proyectos fotográficos de Julio Cortázar lo ejemplifican, es a una sensibilidad urbana. A pesar del voyerismo colonial que busca lo exótico en el Nuevo Mundo, la fotografía en América Latina mantiene un foco urbano, muchas veces en forma obsesiva. Los vaivenes geográficos de Cortázar se convierten en proyectos transatlánticos en los que la insistencia en la ciudad sirve simultáneamente como polo de atracción y blanco de ataque sociopolítico. Aquí me detengo uno de los muchos proyectos fotográficos cortazarianos, Prosa del observatorio (1972), para señalar cómo ejemplifica la problemática de la mirada urbana distanciada. Este libro presenta fotos de lugares donde Cortázar no había vivido, lejos de la familiaridad de Buenos Aires y de París, donde sin embargo la ciudad como constructo europeo de cultura y de escritura interfiere y pesa sobre la imagen.

2 La insistencia en las imágenes y en la representación visual por parte de Cortázar se nota en casi toda su obra. Desde su declaración en "Algunos aspectos del cuento" que compara el cuento corto a una instantánea y la novela a una película, la fotografía persiste como estrategia metaficcional en su obra. El cuento "Las babas del diablo" puede ser el ejemplo mejor elaborado en cuanto a la fotografía, que con su versión cinematográfica, fijó el tema que sus lectores ya llegaron a reconocer desde Rayuela. En ésta, su novela más reconocida, la misma estructura invita una lectura parecida a hojear un álbum fotográfico. Esta metáfora metaficcional se elabora en varios momentos, particularmente en el capítulo 109 cuando Morelli explica que "la llamada realidad, no es cine sino fotografía [...] Al final queda un álbum de fotos, de instantes fijos". Le da al lector la responsabilidad de "rellenar con literatura, presunciones, hipótesis e invenciones los hiatos entre una y otra foto" (532). En "Apocalipsis de Solentiname", lo fantástico surge a través de diapositivas del viaje del protagonista, el mismo Cortázar, a Nicaragua. En cada 
caso, Cortázar explota las posibilidades de la imagen fotográfica para fines políticos, estéticos y estructurales.

3 Además de las alusiones y referencias al arte visual en su ficción, también produce libros híbridos con mucha experimentación con la imagen visual, como los que María de Lourdes Dávila llama "almanaques" (Último round y La vuelta al día en ochenta mundos) o "catálogos" (Territorios y Silvalandia). Lo que distinguen estos catálogos o proyectos "collage", muchas veces colaboraciones con artistas visuales, es la propuesta de una interdependencia que resulta del encuentro entre lo verbal y lo visual. Según Dávila, en estos libros las imágenes visuales nunca ocupan un plano inferior y tampoco sirven simplemente de "adyacencia ornamental" (13). Algunos críticos consideran UR y La vuelta obras "arquitecturales" que con sus imágenes visuales (frecuentemente fotografías) ofrecen distintos "pisos" de significado en conjunto con el texto verbal. Al cuestionar la primacía de ambos modos de representación, lenguaje e imagen conspiran en la construcción de nuevos territorios espaciales.

4 Cortázar contribuye también con sus ensayos en importantes colecciones de fotos urbanas como Buenos Aires, Buenos Aires, de las fotógrafas Sara Facio y Alicia d'Amico, París, ritmos de una ciudad, con fotos de Alecio de Andrade, y Alto el Perú con fotos de Manja Offerhaus. ${ }^{1}$

5 Estas colaboraciones entran dentro de la categoría de álbumes o libros de arte, lo que críticos como Mitchell llaman "el ensayo fotográfico" que requiere "igualdad, independencia y colaboración" entre el texto verbal y las imágenes fotográficas. En Prosa del observatorio, sin embargo, el mismo Cortázar es simultáneamente el fotógrafo y el ensayista ; allí escribe sobre sus propias fotos tomadas en India. La "autoría" de Cortázar tanto de las imágenes como de las palabras hace de este proyecto una especie de grado cero $\mathrm{u}$ "origen" particular en el contexto de su obra visual-verbal.

6 Prosa del observatorio presenta la paradoja de este "origen" singular, tensionado por la distancia cultural y geográfica de un lugar donde nunca vivió. Cortázar carga el texto con una intensidad que explota el grado de proximidad de su autoría con la distancia con respecto a la geografía y a la tradición cultural a las que pertenecen las imágenes, yuxtapuestas al escenario de su revelación en París. A pesar de las vastas diferencias geográficas y estéticas, este proyecto comunica una integración de espacio y lenguaje, con el propósito de expandir horizontes políticos y metafísicos. Prosa del observatorio insiste en el compromiso cortazariano entre lo fantástico y una estética revolucionaria que hace imperativo el arte en un mundo de alienación urbana y poscolonialismo transnacional.

7 Una de las obras menos estudiadas de Cortázar, Prosa marca un momento único en la evolución de su compromiso con el discurso visual. Prosa documenta los observatorios astronómicos de Jai Singh del siglo dieciocho en Delhi y Jaipur, India. Incluye diecinueve fotos de escaleras, rampas, arcos, columnas y plataformas de piedra. La clasificación genérica de esta obra escapa a la fácil definición, y la falta de consenso crítico ha dejado una variedad de consideraciones. Rosario Ferré la denomina un poema en prosa romántico, mientras que otros críticos trazan en ella una convergencia de prácticas discursivas como la científica, la epistolar, la prosa didáctica y la poesía amorosa. Esta convergencia genérica es típica del ensayo cortazariano. Como señala Davi Arrigucci, el ensayo "valendo-se da flutuação atual dos gêneros literários, funde o rigor e a seriedade normalmente bem comportados da crítica à liberdade inventiva da criação" (10). Para Jaime Alazraki, Prosa entrelaza poesía, ensayo y ficción para producir un manifiesto político ("Tema y sistema" 104, 109). Cortázar evita asignarle a Prosa categoría genérica 
alguna, lo que provoca en el lector una reacción a la calidad plurisémica de la obra. Sin desviarnos más en la problemática genérica del libro, sí cabe mencionar su manera de eludir cualquier consenso en relación a nombrar su forma, lo que subraya su agresiva metadiscursividad. ${ }^{2}$ Cortázar ataca el binarismo al trabajar en un medio híbrido; deshace la oposición entre lo visual y lo verbal, entre el ensayo y la ficción, entre el océano y el cielo, y entre occidente y oriente. Y la ciudad, lugar de origen de la cultura letrada, emerge como el blanco de ataque más feroz.

8 En vez del diálogo que caracteriza sus ensayos en colaboración con otros fotógrafos, ${ }^{3}$ Prosa propone una narrativa que proyecta lo verbal y lo visual desde un sólo foco. Lida Aronne-Amestoy denomina las fotos y el texto de Prosa "co-textos", donde "el icono no es soporte, sino matriz de la palabra" (58). Como práctica común en la mayoría de sus libros con fotos, su ensayo no aparece como prefacio ni como introducción antes de las imágenes, sino que el texto se imprime en torno a las fotos que se dispersan por el libro. ${ }^{4} \mathrm{El}$ texto verbal se fragmenta en doce partes; sugiere instantáneas. A veces las pausas verbales (señaladas por espacios en blanco en la página) se acompañan por una vista aérea que combina la distancia visual con un cambio de estilo narrativo o de punto de vista (Prosa 46-47, por ejemplo). El ensayo varía continuamente entre estilos discursivos epistolario, científico, poético -, mientras circunda las fotos. Aparte de menciones de paso sobre los observatorios, el ensayo trata de las anguilas y su migración al océano, con discusiones corolarias sobre la Vía Láctea, críticas del método científico y meditaciones sobre la elasticidad del tiempo y del espacio. El texto visual-verbal resiste cualquier estructura totalizante o unificadora. Hay pocas fotos panorámicas de los observatorios, y ninguna del sitio rodeado de su paisaje. Al contrario, se insiste en curvas, ángulos, esquinas, partes individuales. La expresión híbrida de las fotos y el ensayo manipula la relación sinecdóquica entre las partes y el todo para descentralizar al espectador. En Prosa, Cortázar reconfigura el diseño urbano mientras deshace la oposición binaria entre imágenes visuales y lenguaje.

9 A pesar del foco no-metropolitano de Prosa (señala ciudades en un país en vías de desarrollo con un pasado colonial europeo), como producto cultural no puede escapar al peso de la ciudad. Hay un imperativo cosmopolita que guía la lente de Cortázar ; subraya la perspectiva urbana como una toma de posición comprometida políticamente y, muy lejos de una celebración de este imperativo cosmopolita, su ensayo acompaña sus imágenes bajo la carga de lo urbano.

10 Prosa alaba Jaipur por su diseño urbano cuyo observatorio se encuentra al centro de la ciudad amurallada, fundada en 1727. El ensayo evita descripciones directas de la ciudad y del observatorio, otra estrategia común en los ensayos cortazarianos que demuestran "um discurso biflexo, ambíguo e irônico, a todo tempo mostrando e ocultando aquilo de que trata" (Arrigucci 12). El observatorio, quizá extraño a las nociones occidentales de paisajes urbanos, ocupa una posición central cerca del palacio. El proyecto de Cortázar adopta irónicamente la mirada etnográfica al lanzar Jaipur como paradigma urbano ; destruye así otra oposición binaria convencional entre centro y periferia.

11 Cortázar parece evitar la imposición de su autoridad sobre las imágenes y el texto al incorporar una tensión en torno a sus roles duales. Cuestiona su propia autoridad al mismo tiempo que cuestiona todo discurso autoritario. Duda de la calidad de sus fotos y evita considerarse fotógrafo en una mención al comienzo del libro : 
Las fotos de los observatorios del sultán Jai Singh (Jaipur, Delhi) fueron tomadas en 1967, con una película de mala calidad ; en París, Antonio Gálvez las convirtió en lo que aquí se muestra y que le agradezco. (7)

12 Esta advertencia se organiza según la cronología de la producción de las imágenes visuales. La voz pasiva sirve para subrayar las fotos en vez del fotógrafo. Introduce París como el sitio de la inscripción de las imágenes. Al final del libro, se ve "París, Saignon, 1971" (78), para insistir en la escena de la escritura. La insistencia en el lugar sitúa el proyecto de una forma que pone distancia entre el lector y las fotos, y que identifica a Cortázar con su posicionamiento urbano occidental de París. De la misma manera, el título del libro insiste en la localización en el espacio. Pero el ensayo subvierte las expectativas de una escritura "dentro" del observatorio, y tampoco se trata mucho "del" observatorio en el texto ; las estructuras de Jai Singh sirven como origen y destino, punto de partida y objeto de deseo, en esta trayectoria que se mueve entre el mar y el cielo. Como un anillo de Moebius (mencionado varias veces en el texto), el comienzo y el fin, el interior y el exterior, dejan de distinguirse.

13 Cortázar continuamente yuxtapone los espacios explorados en Prosa con la ciudad. La narración invita a buscar "encuentros fuera de la ley de la ciudad" (66). Las anguilas ocupan una zona particularmente distanciada de lo urbano : "comprenderás que nada de eso puede decirse desde aceras o sillas o tablados de la ciudad" (13). En Prosa admira en las anguilas sus instintos codificados químicamente que parecen desafiar las leyes de la ciencia. A través de este proyecto, ataca el método científico de clasificación de animales por ser comprometido según la política de burocracia urbana. Las anguilas son revolucionarias nadando contra la corriente urbana. Al destacar una ciudad oriental en este proyecto, no ha podido escapar el peso de los modelos occidentales de planificación urbana. Varios historiadores de arquitectura hindú sugieren que Jaipur fue inspirado por ciudades europeas ; uno en particular señala la París de Napoleón III como modelo (Nath 63, 72). Así que el modelo oriental de Cortázar como alternativo a lo occidental parece compartir algunos rasgos con París. Lo urbano provee uno de los discursos inevitables en este proyecto, ya que los avances matemáticos y astronómicos de Jai Singh tanto como la fotografía y la escritura emergen de estructuras urbanas.

14 Tanto el observatorio como el ensayo de Cortázar entrelazan el agua, la tierra y el cielo. Aunque la migración de las anguilas puede parecer un elemento extraño a las preocupaciones de Jai Singh con sus observatorios, resulta que Jaipur se encuentra cerca de Nahagarh cuya cisterna se considera obra arquitectónica de Jai Singh también. El acceso al agua era una preocupación importante en la región, donde se construyeron más de 200 pozos con gradas (stepwells) entre los siglos VII y IX. La historiadora de la arquitectura Morna Livingston describe estos pozos que recuerdan las conexiones fluidas cortazarianas y sus metamorfosis entre los dominios animal y mineral, entre los territorios terrestres, oceánicos y celestiales :

Donde el pozo conecta el sol brillante de la India al agua limpia, dos mundos separados se juntan. Por los corredores de piedra la gente se mueve entre un reino y el otro... La excavación se equilibra con la construcción--un par de opuestos en una serie que incluye cielo y agua, lo sólido y lo líquido, lo vacío y lo lleno. (1)

El agua en el texto de Cortázar contribuye a un contacto entre elementos distintos, y además de su necesidad en una tierra árida el agua termina en una metáfora para el cielo. Otra explotación del agua resulta en la metáfora de la sed de conocimiento : "Jai Singh sabe que la sed que se sacia con el agua volverá a atormentarlo, Jai Singh sabe que solamente siendo el agua dejará de tener sed" (51). La participación de Jai Singh en los 
pozos de grada, y la importancia de ellos en la zona históricamente, le da a una imagen banal (la sed de conocimiento) más fuerza poética.

16 Su insistencia fotográfica en gradas y escaleras -incluida la imagen que inicia el libro (5)-, subraya la importancia de los puentes que conectan reinos físicamente distintos. Lo sólido de la piedra y el mármol puede sugerir un contraste con la fluidez de la Vía Láctea o la migración de las anguilas; sin embargo, tanto el lenguaje visual como el verbal enfatizan las curvas y las rampas. Una foto presenta escaleras paralelas cuyas sombras borran las gradas de cada extremo. La descripción subraya las curvas que dan una fluidez a la estructura :

...la lenta curva de las máquinas de mármol o la cinta negra hirviente nocturna al asalto de los estuarios... que eso que fluye o converge o busca sea lo que es y no lo que se dice: perro aristotélico, que lo binario que te afila los colmillos sepa de alguna manera su innecesidad cuando otra esclusa empieza a abrirse en mármol y en peces, cuando Jai Singh con un cristal entre los dedos es ese pescador que extrae de la red, estremecida de dientes y de rabia, una anguila que es una estrella que es una anguila que es una estrella que es una anguila. (14-16)

17 El vaivén entre las anguilas y las estrellas, probablemente el pasaje más citado de este texto, crea una especie de emblema medieval junto con las gradas sombreadas. Cortázar encuentra en las estructuras de Jai Singh una fluidez física que quiere explotar como metáfora para la metamorfosis y la revolución.

18 En el texto, múltiples imágenes de gradas crean conexiones verticales y sugieren también conexiones conceptuales. Una descripción evoca la bajada al agua pero sinestésicamente gira hacia el cielo al final : "esas interminables teorías de peldaños que Jai Singh escalaba en una lenta caída hacia el cielo" (50). Otro fragmento introduce la "revolución" de las anguilas mientras migran por la profundidad del mar: "es también serpiente negra de ida, lentos peldaños hacia la plataforma que reta el musgo astral, serpiente plateada de regreso" (63). El ensayo borra las distinciones entre reinos líquidos y sólidos para alcanzar una ética revolucionaria : "Todavía es tiempo de sargazos, de guerrillas parciales que despejan el monte sin que el combatiente alcance a ver una totalidad de cielo y mar y tierra" (64). Las gradas conectan pero también sirven la militancia metafísica de Cortázar con sus convergencias fantásticas que dependen de construcciones urbanas mientras simultáneamente las cuestionan.

19 En Prosa del observatorio Cortázar establece una convergencia entre fotografía, astronomía y arquitectura como métodos de escritura que coinciden en su concepto de lo urbano. La fotografía en colaboración con la palabra ofrece sistemas alternativos que requieren nuevas estrategias para leer la realidad. Se ve cómo la fotografía le provee a Cortázar un análogo provocativo a lo fantástico en su ficción. La fotografía según Cortázar "no congela el tiempo como suele decirse ; muy al contrario, lo libera de su versión primaria" (Alto el Perú 49). Si Jai Singh trasciende el espacio terrestre para acercarse al cielo a través de su arquitectura, Cortázar transgrede las fronteras convencionales espaciotemporales por su escritura, y en los proyectos visuales-verbales, a través de la colaboración entre imagen y palabra.

20 Para Cortázar, el concepto cultural de la ciudad se asocia inevitablemente a la escritura. Sus proyectos fotográficos critican la escritura por pertenecer a sistemas discursivos hegemónicos. En Prosa ataca la escritura por perpetuar estructuras discursivas dominantes en productos como diccionarios, tesis doctorales y diarios. Critica a los científicos por "la sórdida paradoja de un empobrecimiento correlativo con la 
multiplicación de bibliotecas, microfilms y ediciones de bolsillo, una culturización a lo jíbaro" (52-54). Las instituciones--bibliotecas, laboratorios científicos académicos, agencias de prensa--que producen, difunden y justifican los productos escriturarios también sufren ataques por restringir modos discursivos y controlar la percepción humana. Critica en particular la institución científica francesa, y en un pasaje del ensayo que se presenta como una carta a la científica Madame Bauchot, la voz narrativa llama la atención sobre la dependencia en "el vendaje de la ciencia" de parte de lectores como "ese hombre que lee el diario y compra libros y quiere saber, entonces la enumeración la clasificación de las anguilas y el fichero de estrellas nebulosas galaxias" (58-9). Al chorro de palabras aquí le falta puntuación, señalando una insuficiencia o una falla en el lenguaje escrito.

21 Sin embargo, tiene que admitir que la fotografía, como sistema semiótico y lenguaje con sus propias convenciones, es otra forma de escritura y de lectura en cuanto inscribe las imágenes y las fija en el papel para que sean descifradas. ${ }^{5}$ Las escaleras de Jai Singh le acercan a las estrellas, y el dominio astral como forma de inscripción en Prosa recuerda la asociación que hace Walter Benjamin entre las estrellas y el lenguaje fotográfico. Benjamin sugiere a menudo metáforas astrológicas para sus teorías del conocimiento (donde las ideas se comparan a constelaciones) y sus teorías del tiempo (mirar una estrella implica viajar por años luz). En el ensayo de Prosa se salta frecuentemente del mar al cielo donde las estrellas funcionan como un alfabeto indescifrable :

Retornar al fragor silencioso de las corrientes submarinos... también el cielo es así en las noches despejadas cuando las estrellas se amalgaman en una misma presión, conjuradas y hostiles, negándose al recuento, a las nomenclaturas, oponiendo una aterciopelada inalcanzabilidad a la lente que las circunda y abstrae, metiéndose de a diez, de a cien en un mismo campo visual... enraizadas en los mitos del cielo. (32-4)

La foto que este fragmento circunda presenta una pared oscurecida por una sombra donde el cielo abierto llena casi la mitad de la imagen. Vistas aéreas o miradas hacia el cielo tienden a acompañar espacios en blanco en el texto verbal. En este ejemplo, una cúpula pequeña sugiere la dimensión minúscula del observador en relación a la estructura total. El movimiento fluido entre lo terrestre y lo celestial transgrede fronteras espaciales para desafiar los límites metafísicos convencionales.

23 Aunque puede parecer que Prosa yuxtapone geografías, culturas y zonas ambientales (el mar y el cielo a lo urbano), Cortázar se apropia del espacio urbano precisamente para borrar estas distinciones. Por ejemplo, en Prosa, el ensayo termina elidiendo el trabajo científico europeo con la astronomía y las matemáticas hindúes :

...puede ocurrir que entremos en los parques de Jaipur o de Delhi, o que en el corazón de Saint-Germain-des-Près alcancemos a rozar otro posible perfil del hombre; pueden pasarnos cosas irrisorias o terribles, acceder a ciclos que comienzan en la puerta de un café y desembocan en una horca sobre la plaza mayor de Bagdad, o pisar una anguila en la rue du Dragon. (54-55)

24 La fotografía, como la arquitectura y la astronomía, depende no sólo del desarrollo industrial y técnico sino también de modos de pensar, infraestructuras y planificación espacial urbanos. Pero en lugar de una revolución que brota en la calle, Cortázar propone una metamorfosis revolucionaria contra la ciudad cuyos escenarios son el mar y el cielo. Las fotografías de los observatorios invitan al lector a pasear por las arcadas y las rampas de Jai Singh hacia una visión alternativa, no exactamente de las estrellas, que no se ven en las fotos, sino más bien una nueva matriz para leer la realidad. 
25 Para Cortázar, la ciencia y la escritura (y yo diría también la fotografía) no se pueden disociar. Como mecanismos de la semiótica urbana, participan de las mismas estructuras políticas e institucionales. Como elabora Sara Castro-Klaren :

La creación científica de la realidad no difiere del compromiso del escritor de explorar y ampliar la noción de la realidad, pues ambos se hallan empeñados en inventar o fabular al mundo y al mismo hombre. La invención para Cortázar se produce dentro del desiderátum de lo desconocido (lo otro). (20)

26 La arquitectura, la astronomía, aun la fotografía que emerge de la experimentación científica dependen no sólo de desarrollo industrial material sino también de modos urbanos de pensamiento, infraestructura de la ciudad, las cartografías físicas del espacio. Jai Singh creó su propio sistema concreto para juntar lo urbano con lo celestial, y Cortázar quiere migrar entre los elementos de la luz, el agua y el aire. Su narración por palabras y fotografías parte de lo urbano y vuelve a lo urbano. Cuestiona estructuras urbanas mientras las explota para su potencial revolucionario. En vez de una revolución urbana de la calle, Cortázar propone una metamorfosis revolucionaria contra la ciudad.

27 Análogo a su manipulación de estructuras de jazz y símbolos de mandalas que se incorporan en Rayuela, la pasión de Cortázar por otros medios continuamente integra la expresión visual en su escritura. Sus maniobras metadiscursivas incluyen lo visual en su lenguaje de representación más allá de la crítica de arte. Concuerdo con Dávila que distingue la crítica de arte, donde "los textos se proponen como una narrativa 'sobre,' 'para,' 'por' y 'desde' las imágenes que los acompañen" (182), del compromiso interartístico de Cortázar con la expresión visual. No se trata de escribir "sobre" las fotos sino de abrazar la expresión visual como corolario o compañero dialogante de lo verbal. El ensayo en Prosa hasta confronta los límites de las palabras :

Que nuevas palabras tranquilizadoras acompañen el asalto de la serpiente a los arrecifes, el avance a los estuarios, la incontenible invasión de los ríos; todo eso que no tiene nombre se llama ya de tantas maneras... (23)

Las palabras terminan siendo metáforas ficcionalizadas por la fotografía en esta crítica elaborada del discurso urbano. En vez de considerarlas herramientas de expresión, las palabras son entidades corrompidas, cómplices sospechosos de las estructuras represivas del léxico científico y de las taxonomías clasificatorias.

29 En su libro en colaboración con Alecio de Andrade, París, ritmos de una ciudad, Cortázar llama a París la ciudad fotográfica por excelencia. Sospecho que la presencia ubicua de la Ciudad Luz en estos ensayos va más allá de un capricho autobiográfico. ${ }^{6}$ Los ensayos fotográficos no sirven para comentar las fotos sino para explorar el propio medio fotográfico, su misión estética y social. Este medio, según Cortázar, desafía diferencias categóricas y prepara el terreno para nuevas conexiones. Cortázar personifica París como mujer orgullosa y vana que inaugura el nuevo medio :

Mucho antes de Nicéphore Niepce, de Daguerre y de Nadar, la ciudad había encontrado ya su imagen fotográfica, la instantánea detención de cualquiera de sus infinitas formas, fiestas y catástrofes... gris como la descubriría al fin la cámara... el perfecto tamiz del blanco y el negro ofreciéndose en toda la gama de sus matices. ( París)

30 Si Daguerre y Atget, Cartier-Bresson y Brassai inventan la fotografía y París, Cortázar reinventa Latinoamérica a través de la lente de París. Se mueve en Prosa entre Jaipur y París con su narración que va de ciudades fotografiadas a ciudades literarias, a ciudades astronómicas, a ciudades nostálgicas, sin precisar su propia pertenencia a las mismas. Cambia de tiempos y espacios para subvertir los modelos socio-históricos del mundo 
poscolonial. Cortázar construye puentes verbales que se expanden para no sólo conectar las fotos. Desconfía de la palabra para preferir la luz, como dice en Prosa del observatorio, "decirse una vez más que la casualidad, esa palabra tranquilizadora, ese otro umbral de la apertura" (Prosa 49). Cortázar asigna a la fotografía sus propios poderes discursivos. Lo visual y lo verbal se juntan para deshacer cualquier orden o correspondencia convencional entre las palabras y las imágenes. Se tienen que leer como las escaleras del observatorio : su curvatura gira en torno a las constelaciones, tan fluida como su prosa, pero también tan fragmentada como las sombras angulares de las tardes. La coincidencia o co-participación de los medios verbal y visual anuncia este umbral urbano donde el lenguaje cede el paso a la imagen porque no puede contra la vasta expansión iluminada, o en las palabras de Cortázar, "todo eso que no tiene nombre [y que] se llama de tantas maneras" (Prosa 23).

\section{BIBLIOGRAFÍA}

Alazraki, Jaime. "Tema y sistema de Prosa del observatorio de Julio Cortázar". La Torre 1.1 (1987) : 92-110.

Alazraki, Jaime. "Tres formas del ensayo contemporáneo : Borges, Paz, Cortázar". Revista de la Universidad de México 17 (1982) : 19-23.

Arrigucci, Davi. Introdução. Valise de cronópio. Julio Cortázar. Trad. Daví Arrigucci. São Paulo : Perspectiva, 1974.

Arrone-Amestoy, Lida. "Identidad y diferencia : discursos de la imagen en Prosa del observatorio". Los ochenta mundos de Cortázar : ensayos. Ed. Fernando Burgos. Madrid : Edi-6, 1987. 55-66.

Bush, Andrew. "Supposing Morelli Had Meant to Go to Jaipur". Julio Cortázar : New Readings. Ed. Carlos J. Alonso. Cambridge : Cambridge UP, 1998. 130-154.

Cadava, Eduardo. Words of Light. Theses on the Photography of History. Princeton : Princeton UP, 1997.

Castro-Klarén, Sara. "Fabulación ontológica : hacia una teoría de la literatura de Cortázar". Escritura, transgresión y sujeto en la literatura latinoamericana. Puebla, México : La Red de Jonás, 1989. 15-29.

Cortázar, Julio. "Algunos aspectos del cuento". Casa de las Américas 15-16 (1962-63). http:// www.literatura.us/cortazar/aspectos.html

Cortázar, Julio. Alto el Perú. Fotografías de Manja Offerhaus. Mexico : Nueva Imagen, 1984.

Cortázar, Julio. Buenos Aires, Buenos Aires. Fotografías de Sara Facio y Alicia d'Amico. Buenos Aires : Sudamericana, 1968.

Cortázar, Julio. Cuentos completos. 2 vols. Madrid : Alfaguara, 1994.

Cortázar, Julio. París : ritmos de una ciudad. Fotografías de Alecio d'Andrade. Barcelona : Edhasa, 1981.

Cortázar, Julio. Prosa del observatorio. 1972. Barcelona : Lumen, 1974. 
Cortázar, Julio. Rayuela. Buenos Aires : Sudamericana, 1963.

Cortázar, Julio. Silvalandia. Ilustraciones de Julio Silva. México : Ediciones Culturales GDA, 1975.

Cortázar, Julio. Territorios. 1978. México : Siglo XXI, 1992.

Cortázar, Julio. Último round. 2 vols. 1969. México : Siglo XXI, 2001.

Cortázar, Julio. Valise de cronópio. Trad. e intro. Daví Arrigucci. São Paulo : Perspectiva, 1974.

Cortázar, Julio. La vuelta al día en ochenta mundos. 2 vols. Madrid : Siglo XXI, 1973.

Dávila, María de Lourdes. Desembarcos en el papel. La imagen en la literatura de Julio Cortázar. Rosario : Beatriz Viterbo, 2001..

Ferré, Rosario. El romántico en su observatorio. San Juan : Literal, 1990.

Franco, Jean. "París, ciudad fabulosa". Novelistas hispanoamericanos dehoy. Ed. John Loveluck. Madrid : Taurus, 1976. 271-90.

Garfield, Evelyn Picón. "Julio Cortázar's Redheaded Night : Or Notes on Ordering the Universe in Prosa del observatorio". Review of Contemporary Fiction 3.3 (1983) : 71-77.

Jones, Julie. A Common Place: The Representation of Paris in Spanish American Fiction 1963-1982.

Lewisburg, PA : Bucknell UP, 1998.

Livingston, Morna. Steps to Water : The Ancient Stepwells of India. Foreward Milo Beach. NY :

Princeton Architectural P, 2002.

Mitchell, W. J. T. Picture Theory. Chicago : U Chicago P, 1994.

Nath, Aman. Jaipur : The Last Destination. Bombay : India Bookhouse, 1993.

Schwartz, Marcy. "Cortázar Under Exposure : Photography and Fiction in the City". Beyond the Lettered City : Latin American Literature and Mass Media. Debra Castillo y José Edmundo Paz-Soldán eds., NY : Garland, 2000. 117-138.

Schwartz, Marcy. Invenciones urbanas : ficción y ciudad latinoamericanas. Buenos Aires : Corregidor, 2010.

Schwartz, Marcy. Writing Paris. Urban Topographies of Desire in Contemporary Latin American Fiction. Albany, NY : SUNY P, 1999.

\section{NOTAS}

1. Véase mi artículo "Cortázar under Exposure" para una discusión de sus proyectos fotográficos sobre París y Buenos Aires. Para comentarios sobre Alto el Perú, véase "La geografía fotográfica de Julio Cortázar entre continentes" en mi libro Invenciones urbanas.

2. Véase ensayos de Bush y Garfield para otras consideraciones genéricas respecto a Prosa.

3. Alazraki identifica la presencia del diálogo como estrategia ensayística de parte de Cortázar en general en su "Tres formas del ensayo".

4. Su ensayo en París, ritmos de una ciudad, que aparece antes de las imágenes, es una excepción.

5. Eduardo Cadava elabora el rol escritural de la fotografía según Benjamin en su libro Words of Light.

6. Para un análisis del rol de París en la obra ficcional de Cortázar, véase mi libro Writing Paris, el libro de Julie Jones y el ensayo de Jean Franco. 


\section{RESÚMENES}

De los muchos proyectos fotográficos de Julio Cortázar, Prosa del observatorio es el único en que él es el autor de las fotos tanto como del ensayo. Una de las obras menos estudiadas de Cortázar, Prosa presenta fotos de los observatorios astronómicos en Jaipur y Delhi diseñados por Jai Singh en el siglo XVIII. Este artículo explora la dinámica verbal-visual de Prosa en el contexto de la mirada urbana que pesa sobre ambos discursos (lo verbal y lo visual). La perspectiva occidental parisina se enfrenta con la perspectiva oriental de Jaipur para desmantelar el imperativo urbano.

Parmi les multiples projets photographiques menés pas Julio Cortázar, Prose de l'Observatoire est le seul où il est à la fois auteur des photographies et de l'essai. L'une des œuvres le moins étudiées par Cortázar, Prose présente des photographies des observatoires astronomiques de Jaipur et de Delhi, dessinés par Jai Singh au XVIIIe siècle. Cet article explore la dynamique visuel/verbal de Prose, dans le conteste d'un regard urbain qui pèse sur les deux discours (le verbal et le visuel). La perspective orientale parisienne se voit confrontée à la perspective orientale de Jaipur, pour démanteler ainsi l'impératif urbain.

Of Julio Cortázar's many photographic projects, only in Prosa del observatorio is he both author and photographer. One of the least studied works by Cortázar, Prosa presents photos of the astronomical observatories in Jaipur and Delhi designed by Jai Singh in the eighteenth century. This article explores the verbal-visual dynamic in Prosa in the context of the urban gaze that weighs on both the verbal and the visual discourse. The Western, Parisian perspective comes up against the Asian perspective of Jaipur to undermine the urban imperative.

\section{ÍNDICE}

Mots-clés: Cortázar, Jai Singh, India, Jaipur, photographie, Paris, ville

Keywords: photography, city

Palabras claves: fotografía, ciudad

\section{AUTOR}

\section{MARCY SCHWARTZ}

Rutgers University 